\title{
Jin-ping Xi's Views on Agriculture, Rural Areas and Farmers
}

\author{
Juan Tang \\ Marxism School of Sichuan University, China
}

Keywords: Jin-ping Xi, agriculture, rural areas, farmers.

\begin{abstract}
Jin-ping Xi combines Marxism with the latest reality of agriculture, farmers and rural areas, and put forward a series of new ideas, innovating and developing the Marxist thought of "agriculture, rural areas and farmers".
\end{abstract}

\section{Introduction}

China's agriculture, rural areas and farmers is still in the background of the primary stage of socialism, as well as in the process of changing from traditional mode to modernization. Specifically, the total amount of agricultural products is basically balanced with the goal of improving the quality, optimizing the structure and increasing the farmers' income. In this stage, it aims to increase the production efficiency and improve the market competitiveness through capital, technology and information resources. The main contradictions of the current stage are manifested in the following aspects, the transformation of agriculture from the total quantity to the structural contradiction, which is characterized by the lack of supply and the shortage of supply; the growth of the farmers' income is weak; the rural infrastructure construction is weak. In recent years, our party and government have introduced a series of policies and measures to promote the agricultural transformation, adjust the structure, promote reform, promote the farmers' income through transfer payments, subsidies and other forms, increase the investment in rural infrastructure construction. However, several problems still exist, for instance, the imbalance of supply and demand of agricultural products, the unreasonable allocation of elements, the growth of farmers' income, the heavy resource and environment pressure. Some contradictions need to be solved, for instance, the increase of production and improvement of quality, the increase of cost and the price downturn, the high inventory and the poor sales; the farmers can only increase the production amount instead of the income; the unsound security system; the farmers' non-farm employment; the urbanization process lag; the poor rural compulsory education, health care, social security.

In the No. 1 Document issued by the CPC Central Committee in 2017, the goals of agriculture, rural areas and farmers were proposed in the new period, that is, on the basis of ensuring food security, we should focus on the market demand changes to increase the income of farmers and ensure the effective supply. We should also promote the agricultural and rural development by the excessive dependence on resource consumption and the demand of the total amount, pursues the ecological sustainability and pay more attention to meet the quality of demand changes. [ No. 1 Document issued by the CPC Central Committee in 2017, Opinions of the CPC Central Committee and the State Council on Further Promoting the Structural Reform of the Agricultural Supply Side and Accelerating the Cultivation of New Energy for Agricultural and Rural Development.] It is a long process to promote the structural reform of the agricultural supply side, the continuous increase of the farmers' income and the benign development of rural social ecology. It is necessary to coordinate the interests of all parties. The key is to deal with the relationship between the government and the market.

Since the $18^{\text {th }}$ National Congress of the Communist Party of China, General Secretary Jin-ping Xi has published a series of important speeches on agriculture, rural areas and farmers in the survey, as 
well as at the meeting, which formed the system of agriculture, rural areas and farmers and made the Marxist ideas with new realm.

\section{To Determine the Development Goals of Agriculture, Rural Areas and Farmers}

Agriculture is the basis of the national economy. Farmers are an important part of our population. Rural areas are the farmers' living regions. These three parts play an important role in national politics, economy and society. Therefore, Jin-ping $\mathrm{Xi}$ pointed out that only a solid agricultural base, harmonious and stabile rural areas, farmers' well living and working environment can contribute to the overall situation. Therefore, $\mathrm{Xi}$ attached great importance to the development of agriculture, rural areas and farmers, to confirm the development goals and the development direction of agriculture, rural areas and farmers. In the central rural work conference held in December 2013, Xi proposed that we must fully build a moderately prosperous society. China should be strong, as well as agriculture; China should be beautiful, as well as rural areas; China should be rich, as well as the farmers. In this meeting, Xi proposed three development goals, that is, strong agriculture, beautiful rural areas and rich farmers.

\section{Make Clear of the Core Task of Agriculture, Rural Areas and Farmers}

After confirming the targets of agriculture, rural areas and farmers, Jin-ping Xi further confirms the tasks of agriculture, rural areas and farmers. The core task is to promote the farmers' income. The most difficult task is to make the farmers out of poverty. Only the farmers' income continues to grow rapidly, will we fully build a well-off society. In poverty alleviation in Fuping County, Hebei Province in 2012, Xi said that we should fully build a well-off society and the most arduous and arduous task is in rural areas, especially in poor areas. Therefore, the core task of agriculture, rural areas and farmers is to promote the farmers to increase their income. The most difficult task is to eliminate the rural poverty and make the farmers out of poverty.

\section{Approaches to Promote the Development of Agriculture, Rural Areas and Farmers}

In order to achieve the development goals of agriculture, rural areas and farmers and the implementation of the development tasks, the Party Central Committee with the core of Jin-ping Xi put forward a series of important ways.

First, the development is the total approach to solve the problem of agriculture, rural areas and farmers. Only development can promote most of the farmers' income, make part of them out of poverty and change the phenomenon of rural poverty in some areas.

Second, the important way of development is that the relevant government policy is to solve the problem of agriculture, rural areas and farmers and to promote the agriculture, rural areas and farmers. First of all, we need to strengthen and consolidate the basic position of agriculture and to protect the investment in agriculture. Jin-ping Xi pointed out that we must increase the investment in agriculture regardless of the financial difficulties. We must ensure that agricultural spending, spending and cannot reduce the investment of agriculture, rural areas and farmers. Furthermore, we should continue to stabilize the government in rural basic operating system. Xi said that the rural basic management system is the cornerstone of the party's rural policy. We should adhere to the party's rural policy. The most important thing is to adhere to the basic rural management system; to speed up the establishment of three-dimensional complex modern agricultural management system. Finally, we should explore the land system reform and create conditions for the scale of agricultural production. Xi said the nature of land public ownership cannot be changed, as well as the red line of cultivated land, the interests of farmers. Therefore, the development can be explored in an orderly manner. In short, Jin-ping Xi advocated creating conditions by strengthening and improving the policy and the development of agriculture, rural areas and farmers.

Third, deepening reform is to solve the problem of agriculture, rural areas and farmers, to promote its development. After years of hard work, China's agriculture, rural development has entered a new 
stage. Agriculture requires further development. It faces the problems of complex international and domestic environment and the agriculture, rural areas and farmers have more internal bottlenecks and obstacles. In this special period, we need to remove the defects in the institutional mechanisms, clear the development path of agriculture, rural areas and farmers. In November $28^{\text {th }}$, 2013, Jin-ping Xi proposed in the eighteenth Central Political Bureau of the second collective study that to solve the problem of agriculture, rural areas and farmers is to deepen the reform, to follow the Chinese characteristics of modern agricultural road. In the new historical stage, the main contradiction of agriculture is structural, especially the lack of supply. The focus of reform is to promote the supply-side structural reform. In December $31^{\text {st }}$, 2016, the CPC Central Committee and State Council issued No. 1 Document that to promote the supply-side structural reform and to improve the quality of agricultural supply as the main direction, to institutional reform and mechanism innovation as a fundamental way. Through institutional reform, we can clear the development of agriculture, rural areas and farmers.

\section{The Development Path of Agriculture, Rural Areas and Farmers}

Agricultural modernization. To achieve a breakthrough development, agriculture must promote agricultural modernization through a variety of ways. During the inspection in Shandong Province from November $24^{\text {th }}$ to $28^{\text {th }}$, 2013, Jin-ping Xi pointed out that the key of the agriculture development is its modernization while the key of the agricultural modernization is the scientific and technological progress. During the inspection in Henan Province from May $9^{\text {th }}$ to $10^{\text {th }}$, 2010, Jin-ping Xi pointed out that the basis of grain production is the arable land; its lifeline is the water; its development trend is science and technology; its motivation is the policy. All these key problems to grasp the implementation and to achieve a new breakthrough in food production.

First, the land is the basis of agricultural production and development. We must maintain the basic stability of the existing cultivated land area and further strengthen the quality of cultivated land protection. Jin-ping $\mathrm{Xi}$ pointed out that we must still adhere to the red line of 18-million-mu cultivated land. The red line includes the amount, as well as the quality. This is an important way to improve the comprehensive agricultural production capacity.

Second, we need to improve the water conservancy and water conservancy project construction and improve agriculture to resist natural disasters and water resources deployment. Jin-ping Xi talked about water conservancy construction, "Water is the lifeblood of agriculture". We must do well in irrigation and water conservancy infrastructure construction, improve the efficiency of water usage, promote the rational allocation of water in the space and improve the agricultural drought and flood capacity.

Third, the agricultural modernization depends on the progress of agricultural science and technology. During the inspection in Shandong Province on November $24^{\text {th }}$, 2013, Jin-ping Xi pointed out that we must pay more attention than ever before and rely on the agricultural science and technology progress, take the connotation of the road of development. Xi also pointed out that to promote the scientific agriculture, we should the principle of increasing the production amount and efficiency, combining the agricultural machinery and agricultural agronomy, the production coordination, so that we can promote the agricultural technology integration, labor process mechanization, production and management information and speed up the construction the technical system with high quality, high quality, high efficiency, ecological and safety which is in accordance with the agricultural development requirements.

Fourth, the key to the realization of agricultural modernization lies in people, that is, farmers engaging in production. Being an important factor in the production, farmers are changing from the traditional farmers to the modern professional ones, which is the key to the implementation of policies and technologies. Agricultural modernization requires the young people. After training, they can grow into the farming experts, agricultural operations experts, technology leaders, agricultural marketing talent, agricultural management personnel, so that the status of rural labor can adapt to the changes in agriculture and adapt to the new changes in resource allocation. Therefore, the agriculture will develop; the farmers will increase their income and the rural areas will become rich. 
Construction of new rural areas. We have explored the construction of rural areas since the 1950s. In the new historical background, the Fifth Plenary Session of the $16^{\text {th }}$ CPC Central Committee held on October $8^{\text {th }}$, 2005 adopted the Eleventh Five-Year Plan, which proposed that we should push forward the construction of new socialist countryside in accordance with the principle of production and development, living well, rural civilization, clean and tidy village, management democracy. Jin-ping $\mathrm{Xi}$ pointed out that the rural construction should actively inherit the rural civilization and local culture, retain the pastoral scenery, promote the development of modern agriculture, achieve the harmonious development of man and nature, so that the rural areas will become a happy home for the well-being of farmers. The construction of new socialist countryside is the foundation of the construction of the new rural areas. The rural civilization is the basic requirement of the construction of the rural spiritual civilization. The clean and tidy village is the inevitable requirement of the harmonious development of man and the environment. The democratic management is the political guarantee of the new rural construction. The fundamental goal of rural construction is also the basic measurement of our work.

Ways to make farmers get out of poverty and become richer. Making farmers become rich is the fundamental goal of the agricultural development and the rural construction. It is a long-term and difficult task to promote the increase of the farmers' income. It is necessary to establish an effective way for farmers to increase their income.

First, to accurate poverty alleviation. Poverty alleviation work is an effective way to reduce the poverty of the farmers, which should be planned and effective.

Second, to raise the farmers' income. The farmers' income includes their operating income and property income. On one hand, to improve the efficiency of the agricultural production is an important way for the farmers to increase their income. Food production is the basis of the agricultural production. Thus, we should stabilize the food production and make the farmers profitable. Jin-ping Xi pointed out that whether the farmers are willing to grain and how much they grain relies on how much income it will bring to the farmers. On the other hand, increasing the farmers' property income is an important way to promote their income. The property owned by the farmers mainly include the right to use land and homestead. Through the deepening of rural land property rights, homestead use rights related to the reform of the system, we can give the farmers more land property rights, real estate and financial property rights and increase the farmers' property income.

Third, to increase the wage income of farmers. This is an important way to promote the farmers' income. After the reform and opening up, a large number of farmers become migrant workers. The wage income has become an important source of the farmers' income. In the new period of socialism construction with Chinese characteristics, the fundamental transfer of rural surplus labor force, the reduction of agricultural population and the promotion of peasant citizenship are the effective advancement of increasing the farmers' income.

Fourth, to increase the government transfer payments and increase the farmers' transfer payment income. It is an important way to increase the income of farmers by increasing the transfer payment system of agriculture, rural areas and farmers and perfecting the transfer payment system such as agricultural subsidy. Jin-ping Xi pointed out that we should also continue to improve the specific operation of the transfer payment approach, for instance, to adjust the optimization of subsidies, to improve the accuracy and direction of subsidies, to explore the formation of agricultural subsidies and food production which is linked to the mechanism. All these can not only promote the farmers' income, but also promote the agricultural production.

\section{References}

[1] No. 1 Document issued by the CPC Central Committee in 2013, Opinions of the CPC Central Committee and the State Council on Accelerating the Development of Modern Agriculture and Further Enhancing the Vitality of Rural Development. 
[2] No. 1 Document issued by The CPC Central Committee in 2014, Opinions on Quickening Rural Reform and Speeding up Agricultural Modernization.

[3] No. 1 Document issued by The CPC Central Committee in 2015, Opinions on Speeding up the Reform and Innovation and Speeding up the Agricultural Modernization Construction.

[4] National Medium and Long Term Plan for Food Security (2008-2020).

[5] Report of the Seventeenth National Congress of the Communist Party of China, Highly Holding the Great Banner of Socialism with Chinese Characteristics and Striving to Win the New Victory of Building a Well-off Society in the Country.

[6] National Main Functional Area Planning (2010-2020).

[7] Decision of the Third Plenary Session of the Eighteenth Central Committee of the Communist Party of China, Unswervingly Following the Path of Socialism with Chinese Characteristics and Striving to Build a Well-off Society in an All-round way.

[8] Rural Social and Economic Investigation Division, National Bureau of Statistics. China rural poverty monitoring report (2010) [M]. Beijing: China Statistics Press, 2011.

[9] The Eleventh Five-Year Plan for the National Economic and Social Development of the People's Republic of China.

[10] The Twelfth Five-Year Plan for the National Economic and Social Development of the People's Republic of China.

[11] No. 1 Document issued by The CPC Central Committee in 2017, Opinions of the CPC Central Committee and the State Council on Further Promoting the Structural Reform of the Agricultural Supply Side and Accelerating the Cultivation of New Energy for Agricultural and Rural Development. 